\title{
Avogadro Program for Chemistry Education: To What Extent can Molecular Visualization and Three-dimensional Simulations Enhance Meaningful Chemistry Learning?
}

\author{
Baraa Rayan ${ }^{1}$, Anwar Rayan ${ }^{1,2,3, *}$ \\ ${ }^{1}$ Science Education Department, Al-Qasemi Academic College, Baka EL-Garbiah, Israel \\ ${ }^{2}$ Institute of Applied Research- the Galilee Society, 20200 Shefa-'Amr, Israel \\ ${ }^{3}$ Head of Drug Discovery Informatics Lab, QRC - Qasemi Research Center, Al-Qasemi Academic College, Baka EL-Garbiah, Israel \\ *Corresponding author: a_rayan@qsm.ac.il
}

\begin{abstract}
In developing this study, we hypothesized that the integration of computerized techniques and modeling tools into traditional face-to-face instruction can produce a better hybrid model of teaching, capable of motivating students and improving their attitude toward science in general, and toward chemistry in particular. We tested how molecular visualizations and three-dimensional simulations affect students' conceptual understanding of chemistry and their attitudes toward learning chemistry. During the academic year 2016-2017, we incorporated Avogadro software into teaching and tested how it affected students' performance on chemistry exams in their courses. The difference in average scores between the two groups (8.2 points for the experimental group and 6.4 points for the control group) was significant. Student feedback following the initiative was positive and encouraging. Most students indicated that learning chemistry with Avogadro was extremely helpful, bringing the microscopic world of molecules closer to them, and they felt that they would like to see such software integrated into their chemistry studies from day one. Other parameters will be tested in continuation of this study, such as students' attitudes toward learning chemistry and their inquiry skills.
\end{abstract}

Keywords: chemistry education, molecular structure, computer-based learning, three-dimensional simulations, meaningful chemistry learning, Avogadro software

Cite This Article: Baraa Rayan, and Anwar Rayan, “Avogadro Program for Chemistry Education: To What Extent can Molecular Visualization and Three-dimensional Simulations Enhance Meaningful Chemistry Learning?.” World Journal of Chemical Education, vol. 5, no. 4 (2017): 136-141. doi: 10.12691/wjce-5-4-4.

\section{Introduction}

Chemistry is a difficult subject, since much knowledge in this field concerns the molecular level, and students are expected to think on that scale (in terms of interactions between individual atoms and molecules) to explain phenomena on the macroscopic scale [1,2,3], In addition, they must link the two-dimensional and three-dimensional structures of molecules with their physical properties (such as their physical states, boiling and melting points, density, and color) and their chemical properties (coordination number, chemical stability, and so forth). All these things should be "cooked" into the mind if one is to understand chemistry well. During the seventies and eighties, a new era of modeling, molecular visualization, and three-dimensional simulations was born. Most of these computerized tools were implemented largely by researchers to help them understand, explain, and predict chemical phenomena $[4,5,6]$.

There is an increasing recognition of the need to foster teaching approaches that enhance the quality of student learning, and since learning is a process of making sense of the topic under study, we presume that teaching chemistry through molecular visualization and three-dimensional simulation tools may be more effective than traditional approaches. When teaching chemistry courses in most education colleges, lecturers still use textbooks and two-dimensional pictures to depict molecules. However, many researchers claim that still pictures are not adequate for building a mental model of new concepts and phenomena and that utilizing dynamic pictures is essential to promoting conceptual understanding [7]. Researchers have found that integrating visual representations such as computerized molecular models, simulations, and animations into the teaching of science may promote students' understanding of unobservable phenomena [8], and afford them the opportunity to make abstract concepts visible. Manipulating chemical structures in the form of two- and three-dimensional representations can help students relate the macroscopic, microscopic, and symbolic representation levels of chemicals to each other [8], and it can enhance students' conceptual understanding and spatial ability [9].

Science in general and chemistry in particular are taught mostly through direct instruction involving the 
delivery of information from the teacher to the student, through lectures, which involve little student interaction with content. This method of teaching is less effective and should be revolutionized. Teaching should be linked to learning and should produce understanding. The information being taught should make sense to the students. With three-dimensional modeling, we can communicate effectively with students, facilitating the interactions between them and chemical terms and concepts. Conceptual terms such as chemical bonding, Van Der Waals (VDW) interactions, polar interaction, $\pi$-stacking interactions, and so forth, will be better understood. Take the concepts of evaporation, condensation, and boiling as an example. Many students do not understand these ideas. They lack a conceptual understanding of what happens after water molecules leave a liquid or the body during the evaporation process, compared to what happens when water molecules leave a liquid in the boiling process. How is one to explain chemically the sentence "Sweating is the body's natural way of regulating temperature"? Students may also have difficulty understanding why water drops form on the outside of a cold drink on a hot summer day. We believe that one of the secrets of internalizing a concept/term is seeing its relationship to a phenomenon.

To assess conceptual understanding, examinations should include questions or activities that prompt students to interact intellectually with concepts or terms. They may need to share some of their own thoughts. This is more likely to result in better assessment of conceptual understanding. In chemistry, terms such as energy, evaporation, heat, and corrosion, are labels for concepts. Concepts are fundamental building blocks of thought that have depth. A concept can become an idea. For example, the concept of condensation becomes an idea when we associate water vapor in the air reappearing as a liquid when it comes in contact with a cool object. Converting concepts into ideas is essential to meaningful learning and conceptual understanding. When students understand a concept well and successfully internalize it, they can (1) think with the concept, (2) utilize the concept in other areas, (3) say it in their own words, (4) find an analogy or a metaphor for the concept, and maybe (5) construct a mental or physical model of the concept. This is what we mean by conceptual understanding at high levels.
Models in general and three-dimensional models in particular, are frequently developed with the aim of approximating the real thing, in a form that can be used and studied in cases when a real situation cannot. Models help students better internalize concepts, clarify, and explain their ideas. Recently, educators in the field of biology outlined a proposal [10] to modernize biology education by addressing a conceptual understanding of key concepts, such as the relationship between structure and function. For this purpose, they highlighted the necessity of utilizing modeling techniques and molecular dynamics simulations to illustrate the links between the structure of proteins and their function [11]. In chemistry, we believe that computerized techniques for molecular visualization and $3 \mathrm{D}$ simulations can play an important role in the training portfolios of students learning to teach chemistry. In this study, we assess the extent to which incorporating molecular visualization and 3D simulations into learning chemistry will improve the understanding of conceptual terms. Table 1 summarizes some of the wellknown tools for modeling, molecular visualization, and 3D simulation.

Developing a favorable attitude in students towards science has often been listed as one of the important goals of science teaching [12,13,14]. Movahedzadeh [15] claims that in order to motivate students and improve their attitudes toward science, instructors ought to redesign their traditional courses using a hybrid model (i.e., integrating of some of the conveniences of online learning with traditional face-to-face instruction in the learning process). We think that integration of computerized techniques and modeling tools with the traditional face-to-face instruction in chemistry can serve as a good hybrid model.

The main objective of this study was to examine how integrating tools for molecular visualization and three-dimensional simulation into chemistry courses at the college level may affect students' conceptual understanding of chemistry and their attitudes toward learning chemistry. In so doing, we can assess the importance of utilizing computerized tools for molecular visualization and threedimensional simulation in general, and the Avogadro program in particular, as they relate to the learning of chemistry in college.

Table 1. Molecular modeling and 3D simulation programs running on the Microsoft Windows platform

\begin{tabular}{|l|l|l|}
\hline Program & Information & Valuable remarks \\
\hline Avogadro & Avogadro project team & $\begin{array}{l}\text { Free software } \\
\text { (Ref: [16]) }\end{array}$ \\
\hline Discovery Studio & Accelrys & $\begin{array}{l}\$ \$ \$, \\
\text { However, Discovery Studio Visualizer, which is a tool for viewing, } \\
\text { sharing, and analyzing protein and modeling data, is free of charge. } \\
\text { (Link: http://accelrys.com/products/collaborative-science/biovia- } \\
\text { discovery-studio/simulations.html) }\end{array}$ \\
\hline PyMol & $\begin{array}{l}\text { A molecular visualization system on an open } \\
\text { source foundation, maintained and distributed by } \\
\text { Schrödinger }\end{array}$ & $\begin{array}{l}\text { \$\$\$ } \\
\text { (Ref: [17]) }\end{array}$ \\
\hline SYBYL-X & $\begin{array}{l}\text { SYBYL-X was developed by TRIPOS and } \\
\text { provides capabilities for small molecular, as well } \\
\text { as macromolecular, modeling and simulations }\end{array}$ & $\begin{array}{l}\text { \$\$\$ } \\
\text { (Link: http://tripos.com/tripos_resources/fileroot/pdfs/SYBYL- } \\
\text { X\%20Suite_FINAL.pdf) }\end{array}$ \\
\hline BALL and BALLView & $\begin{array}{l}\text { BALL is computer software for molecular } \\
\text { modeling and computational structural } \\
\text { bioinformatics }\end{array}$ & $\begin{array}{l}\text { Free } \\
\text { (Ref: [18]) }\end{array}$ \\
\hline Ascalaph Designer & $\begin{array}{l}\text { Ascalaph Designer is a program for molecular } \\
\text { modeling and dynamics simulation }\end{array}$ & Free \\
\hline
\end{tabular}




\section{Methods}

Avogadro is an advanced molecule editor and visualizer, designed for use in computational chemistry, molecular modeling, bioinformatics, materials science, and other related areas [19]. It can be utilized by students for the molecular visualization and three-dimensional simulation of molecules; the user can minimize their tertiary structures and view them from every conceivable angle and perspective (see Figure 1). However, the utility of Avogadro in chemistry and biology education has not yet been studied.

Avogadro has a friendly graphical interface that can be easily manipulated by the user to view the structures of molecules from various angles, in three dimensions. It is quite entertaining for students to create their own varicolored structures, which look good, and this may prompt them to start asking questions and link structures to properties (see Figure 2 -Figure 4). This tool can bring students closer to molecules, revealing details at the microscopic level, and bring them closer to a better understanding of the laws of chemistry, chemical properties, chemical reactions, and other phenomena of chemistry. For example, the user can learn via 3D simulations why the trans-2-butene isomer is more stable than the cis-2-butene isomer (see Figure 2). The aim here is to lead the student to realize that the two-methyl groups in the cis-isomer are closer, leading to steric strain, while in the trans-isomer, the two methyl groups are on opposite sides, resulting in no steric interaction. Using the space-filling model provided by Avogadro can make this better understood. As well, the surface area of trans-2-butene is larger, and there is a linear correlation between the surface area of a chemical and its melting point. The melting point of trans-2-butene is $-105.5^{\circ} \mathrm{C}$, while the melting point of cis-2-butene is $-138.9^{\circ} \mathrm{C}$. However, the boiling point of trans-2-butene is $0.9^{\circ} \mathrm{C}$, while boiling point of cis-2-butene is $3.7^{\circ} \mathrm{C}$. This is explained by polar-polar interactions. Trans-2-butene is non-polar, while cis-2-butene is polar. In the solid phase, the VDW interactions predominate, due to well-order backing and closer contacts, while in the liquid phase polar-polar interactions predominate, due to less-order backing and lesser contacts between molecules.

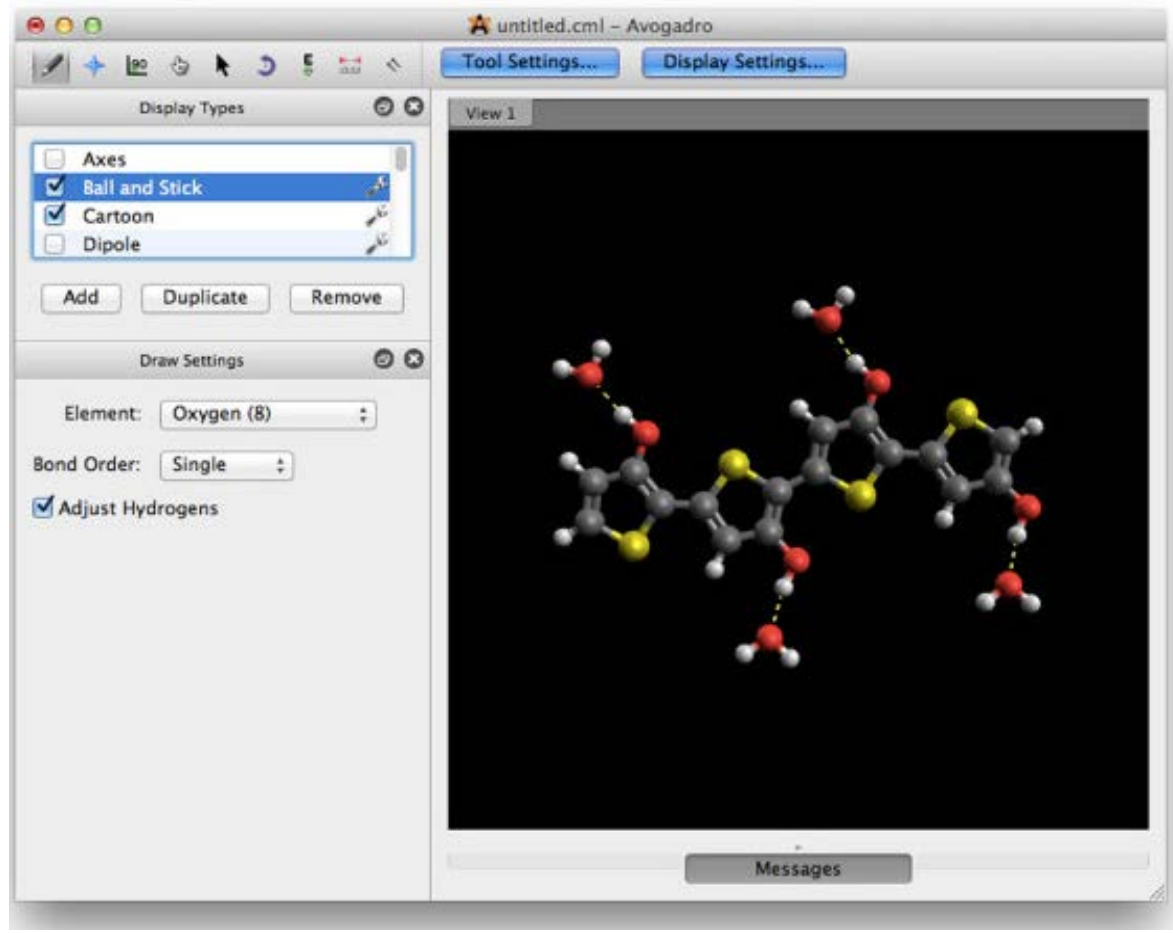

Figure 1. The Avogadro graphical user interface<smiles>CC=CC</smiles><smiles>C/C=C\C</smiles>

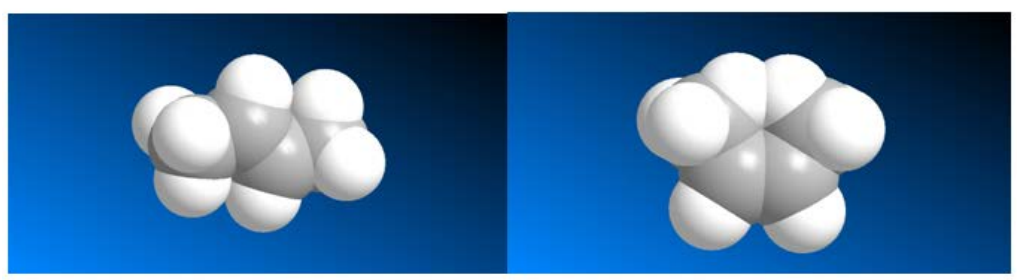

(a)

(b)

Figure 2. Two isomers of 2-butene: (a) trans-2-butene and (b) cis-2-butene. Carbon atoms are colored gray; hydrogen atoms are colored white. Why is trans-2-butene more stable than cis-2-butene? Note: See clashes between hydrogen atoms in cis conformer 
<smiles>CCCCC</smiles>

n-pentane

pentane<smiles>CCC(C)C</smiles>

2-methyl butane isopentane<smiles>CC(C)(C)C</smiles>

2,2-dimethyl propane neopentane

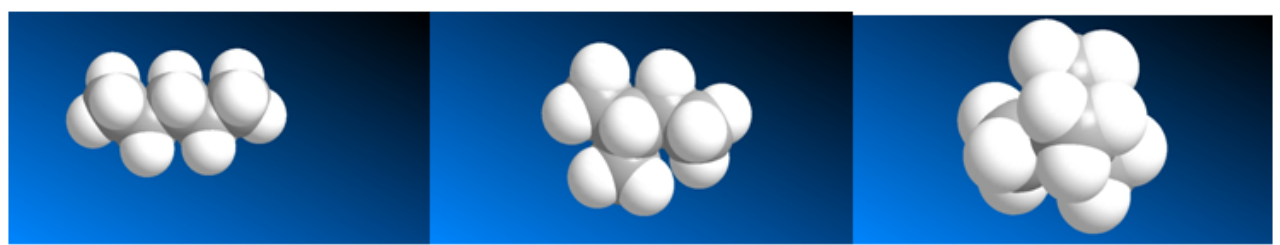

Figure 3. How branching affects the boiling point (the correlation between Van Der Waals interactions and surface area). The surface area decreasing while going from left to right and thus the boiling point
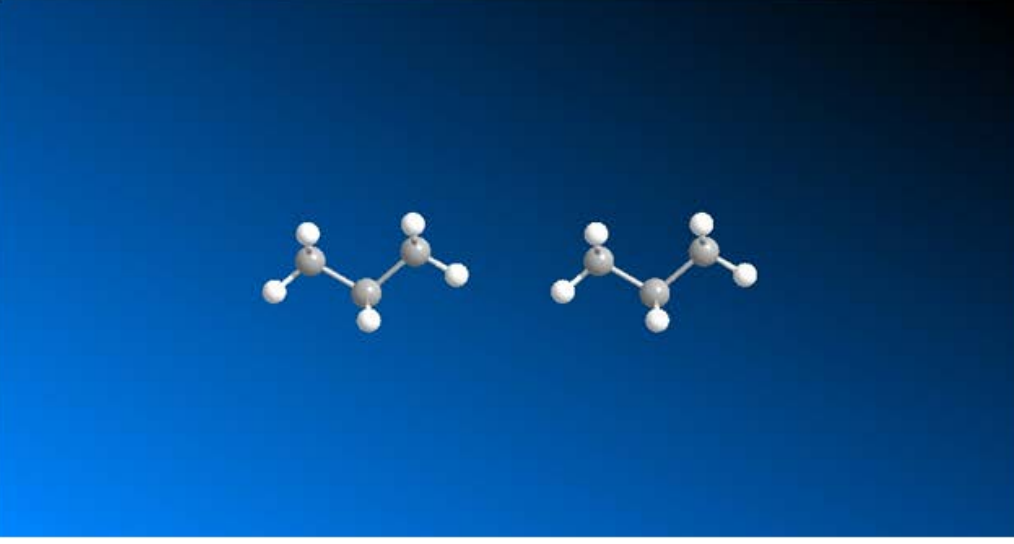

a)

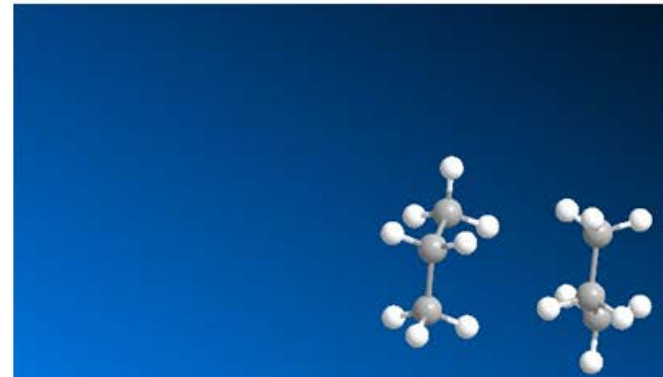

b)

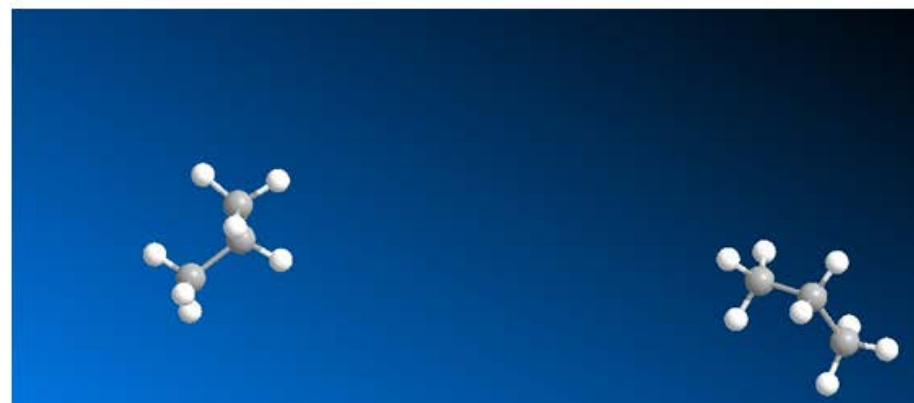

c)

Figure 4. Interaction between two molecules of propane: (a) simulation of the interactions between two propane molecules; (b) at a low temperature $\left(100{ }^{\circ} \mathrm{K}\right)$, both molecules get closer, while (c) at a high temperature $\left(60{ }^{\circ} \mathrm{K}\right)$, the molecules move away from each other. At high temperatures, the kinetic energy is high and overcomes the VDW interaction 
Figure 3 shows how branching affects the boiling point of a compound (a type of correlation between Van Der Waals interactions and surface area). Being able to visualize the tertiary structures of isomers illustrates the chemical logic behind the answer. Molecular visualization by the Avogadro program and three-dimensional simulation of the structures can play a central role in internalizing the chemical concepts of Van Der Waals and steric interactions.

Drawing chemicals with Avogadro software is very easy. We select the Draw Tool and build the molecule from atoms and fragments. The number of hydrogen atoms bonded to each heavy atom can be automatically adjusted to satisfy valency by checking the Adjust Hydrogens box. Once the molecular structure is complete, we are able to perform a fast geometry optimization easily by clicking on the Optimize Geometry icon. Alternatively, we can combine the Auto Optimization tool with the Draw Tool. This is a unique way to manipulate the molecule, while the geometry is constantly minimized in the background. We can observe interactively the effects of changing bond orders and adding/removing groups.

Our research population included first-year college students from Al-Qasemi Academic College who were enrolled in chemistry courses (twenty-two students took part in this research). They were divided into two equal groups: (a) an experimental group, in which students used molecular visualization and 3D simulations in chemistry learning, and (b) a control group, in which students learned chemistry via the traditional approach by observing two-dimensional pictures in textbooks only, without the aid of computerized tools for molecular visualization and 3D simulation. It is worth noting that about half of the students had not studied chemistry before, and none had experience with three-dimensional models or in silico tools for modeling purposes. This was the first time the students heard about computerized techniques for modeling chemicals and predicting properties. The division into groups was done randomly with the use of college admissions data, to ensure that both groups were very close. As well, students who had studied chemistry before were distributed equally between the two groups. The experimental group took part in two workshops (two hours each) to learn the features of the Avogadro program; the control group continued studying chemistry without the aid of such tools. The dependent variable was students' performance on examinations; the independent variable consisted of the methods and strategies for learning chemistry in a college of education.

\section{Results and Discussion}

The aim of the current study was to learn to what extent molecular modeling and three-dimensional simulations can enhance chemistry learning in colleges of education and simplify students' understanding of chemistry concepts. As discussed in the introduction, during the last couple of decades, many computerized tools for molecular visualization and three-dimensional simulation have been developed and applied mainly by researchers in the academic and industrial sectors. One of these tools is the Avogadro program. We tested its incorporation into chemistry teaching and measured how it affects college-students' understanding of chemistry and their attitudes toward studying science in general, and chemistry in particular. Comparisons of the students' performance on the course examinations for both the experimental and control groups are presented in Table 2; the results show significant differences between the groups in favor of the experimental group that used Avogadro.

Table 3 shows the average scores and the standard deviations of the experimental and control groups on the chemistry examinations, with regard to certain topics related to intermolecular interactions and physical properties (such as the boiling point/ melting point), molecular stability, configurations and polarity, resonance and chemical stability, and functional groups in given organic compounds.

The findings show clearly that incorporating Avogadro software into chemistry education may contribute to increasing students' understanding of chemistry and improve their performance on examinations. As well, through this study, we concluded that linking lecture content with hands-on molecular modeling by Avogadro-namely, seeing and doing-enhances students' understanding of conceptual chemical terms and provides them with the necessary skills for three-dimensional visual literacy and for understanding the linkages between chemical structures at the microscopic level and physico-chemical properties seen at the macroscopic level. The use of modeling tools in chemistry education can play a central role in corroborating what is being learned and bringing scientific knowledge closer to students.

Table 2. Comparisons of the examination scores of the experimental and control groups. The average score of the experimental group was significantly higher than that of the control group

\begin{tabular}{|l|c|c|c|c|}
\hline Group & $\mathrm{N}$ & Average & Standard Deviation & P-value(calculated by ANOVA test) \\
\hline Experimental & 11 & 74.7 & 6.1 & 0.015 \\
\hline Control & 12 & 64.5 & 11.4 & \multirow{2}{*}{0} \\
\hline *P-value $<0.05$ means significant & \\
\hline
\end{tabular}

Table 3. Students' performance on certain topics

\begin{tabular}{|c|c|c|c|}
\hline Topic & $\begin{array}{c}\text { Average } \\
\text { (Experimental/ Control) }\end{array}$ & $\begin{array}{c}\text { Standard Deviation } \\
\text { (Experimental/ Control) }\end{array}$ & $\begin{array}{c}\text { P-value } \\
\text { (calculated by ANOVA test) }\end{array}$ \\
\hline Configurations and polarity & 85.6/73.7 & $9.1 / 10.9$ & 0.01 \\
\hline Molecular stability & $67.8 / 55.8$ & $6.6 / 15.6$ & 0.029 \\
\hline Intermolecular interactions and physical properties & $76.2 / 62.3$ & 8.6/11.6 & 0.004 \\
\hline Resonance and chemical stability & $68.2 / 57.3$ & $5.3 / 15.0$ & 0.034 \\
\hline Functional groups in given organic compounds & 75.9/73.1 & $9.5 / 12.9$ & 0.559 \\
\hline
\end{tabular}




\section{Student Feedback}

Upon completion of the initiative, students from the experimental group were asked for their opinion on the use of modeling tools in chemistry teaching, and the Avogadro tool in particular, and on how this tool contributed to their conceptual understanding of chemistry and their performance on chemistry exams. The students said that the Avogadro tool was helpful in learning chemistry and achieving a good understanding of conceptual terms. They recommended its incorporation into chemistry teaching from day one for all science students. See below few quotations of what students from the experimental group say regarding the use of modeling tools in chemistry teaching:

- " "It is helpful and very easy to use/ learn."

- "Learning chemistry with modeling tool is extremely helpful. Much better than still pictures."

- "I like it. Avogadro make the world of molecules closer to me."

\section{Conclusions}

We conclude that incorporating modeling tools such as Avogadro software into chemistry education might be helpful, bringing the microscopic world of molecules closer to students. The difference in average scores between the two experimental groups (8.2 points for the experimental group and 6.4 points for the control group) is significant. The students' feedback following the initiative was positive and encouraging. Other parameters could be tested in continuation of this study, such as students' attitude toward learning chemistry and inquiry skills.

\section{Acknowledgements}

We acknowledge Al-Qasemi Research Foundation and the MOFET Research Foundation for supporting this research.

\section{Disclosure}

The authors declare that they have no conflict of interests.

\section{References}

[1] Chandrasegaran AL, Treagust DF, \& Mocerino M. (2008). An evaluation of a teacher intervention to promote students' ability to use multiple levels of representation when describing and explaining chemical reactions. Research in Science Education, 38(2), 237-248
[2] Dori YJ, \& Hameiri M. (2003). Multidimensional analysis system for quantitative chemistry problems - symbol, macro, micro and process aspects. Journal of Research in Science Teaching, 40, 278302.

[3] Dori Y.J. and Kaberman Z. (2012). Assessing high schoo chemistry students' modeling sub-skills in a computerized molecular modeling learning environment. Instructional Science, 40, 69-91.

[4] Pappalardo M, Rayan M, Abu-Lafi S, Leonardi M.E, Milardi D, et al. (2017). Homology-based modeling of rhodopsin-like family members in the inactive state: structural analysis and deduction of tips for modeling and optimization. Molecular Informatics. 2017 Apr 4.[Epub ahead of print]

[5] Michaeli A, \& Rayan A. (2016). Modeling ensample of loop conformations by Iterative Stochastic Elimination, Letters in Drug Design and Discovery. 13(7): 646-651.

[6] Goldblum A, Glick M, \& Rayan A. (1993). Extending Crystallographic Information with Semiempirical Quantum Mechanics and Molecular Mechanics: A Case of Aspartic Proteinases. J. Chem. Inform. Comp. Sci. 33(2): 270-274.

[7] Barak M, \& Hussein-Farraj R. (2012). Integrating model-based learning and animations for enhancing students' understanding of proteins structure and function. Research in Science Education, 43(2), 619-636.

[8] Gilbert JK. (2005). Visualization: A metacognitive skill in science and science education. Visualization in Science Education, Models and Modeling in Science Education. 1: 9-27. Publisher: Springer Netherlands.

[9] Barak M, \& Dori YJ. (2011). Science education in primary schools: Is an animation worth a thousand pictures? Journal of Science Education and Technology, 20(5), 608-620.

[10] AAAS. (2011). Vision and Change in undergraduate biology education. Retrieved from http://visionandchange.org/files/2011/03/Revised-Vision-andChange-Final-Report.pdf.

[11] Spitznagel, B., Pritchett, P.R., Messina, T.C., Goadrich, M., Rodriguez, J. (2016). An undergraduate laboratory activity on molecular dynamics simulations. Biochem Mol Biol Educ. doi: 10.1002/bmb.20939. [Epub ahead of print].

[12] Hofstein A, \& Mamlok-Naaman R. (2011). High-School Students' Attitudes toward and Interest in Learning Chemistry. 2011 international year of chemistry. Educ. quím., publicado en línea el 19 de enero de 2011, Universidad Nacional Autónoma de México.

[13] Mamlok-Naaman R. (2011). How can we motivate high school students to study science? Science Education International. 22:1, 5-17.

[14] Raiyn J, \& Rayan A. (2015). How Chemicals' Drawing and Modeling Improve Chemistry Teaching in Colleges of Education. World Journal of Chemical Education 3, 1: 1-4.

[15] Movahedzadeh F. (2011). Improving Students' Attitude Toward Science Through Blended Learning. Science education and civic engagement 3:2, 13-19.

[16] Hanwell MD, Curtis DE, Lonie DC, Vandermeersch T, Zurek E, et al. (2012). Avogadro: an advanced semantic chemical editor, visualization, and analysis platform. Journal of Chemoinformatics 4, 1-17.

[17] Baugh EH, Lyskov S, Weitzner BD, \& Gray JJ. 2011. Real-time pymol visualization for rosetta and pyrosetta. PLoS One, 6(8), e21931.

[18] Moll A, Hildebrandt A, Lenhof HP \& Kohlbacher O. (2005) Ballview: An object-oriented molecular visualization and modeling framework. J Comput Aided Mol Des, 19(11), 791-800.

[19] Milner N, Ben-Zvi R, \& Hofstein A. (1987). Variables that affect students enrollment in science courses. Research in Science and Technological Education, 5, 201-208. 